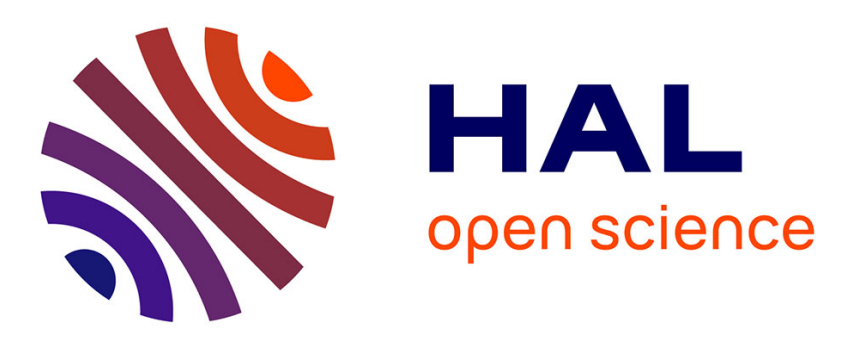

\title{
Uncertainty quantification of wind turbine wakes under random wind conditions
}

Tássia Penha Pereira, Stephen Ekwaro-Osire, João Paulo Dias, Nicholas J

Ward, Americo Cunha Jr

\section{- To cite this version:}

Tássia Penha Pereira, Stephen Ekwaro-Osire, João Paulo Dias, Nicholas J Ward, Americo Cunha Jr. Uncertainty quantification of wind turbine wakes under random wind conditions. ASME 2019 International Mechanical Engineering Congress and Exposition (IMECE2019), Nov 2019, Salt Lake City, United States. hal-02388513

\section{HAL Id: hal-02388513 https://hal.science/hal-02388513}

Submitted on 2 Dec 2019

HAL is a multi-disciplinary open access archive for the deposit and dissemination of scientific research documents, whether they are published or not. The documents may come from teaching and research institutions in France or abroad, or from public or private research centers.
L'archive ouverte pluridisciplinaire HAL, est destinée au dépôt et à la diffusion de documents scientifiques de niveau recherche, publiés ou non, émanant des établissements d'enseignement et de recherche français ou étrangers, des laboratoires publics ou privés.

$$
\text { Copyright }
$$




\section{UNCERTAINTY QUANTIFICATION OF WIND TURBINE WAKES UNDER RANDOM WIND CONDITIONS}

\author{
Tássia Penha Pereira, Stephen Ekwaro-Osire ${ }^{1}$, \\ João Paulo Dias, Nicholas J. Ward \\ Department of Mechanical Engineering \\ Texas Tech University \\ Lubbock, TX, USA
}

\author{
Americo Cunha Jr. \\ Institute of Mathematics and Statistics \\ Rio de Janeiro State University \\ Rio de Janeiro, RJ, Brazil
}

\begin{abstract}
Understanding and minimizing the uncertainties in the wind energy field is of high importance to reduce the reliability risks and financial risks of wind farm projects. The present work aims to observe the levels of uncertainty in modeling the wake effect by attempting to perform statistical inference of a wake parameter, the wind speed deficit. For this purpose, an uncertainty propagation framework is presented. The framework starts by randomly sampling mean wind speed data from its probability density function (PDF), that is fed an inflow model (TurbSim), resulting in random full-flow fields that are integrated into an aeroelastic model (FAST), which results in the variability of the power and thrust coefficients of a wind turbine. Such coefficients and wind data, finally, fed the wake engineering model (FLORIS). The framework ends with the determination of the $95 \%$ coefficient intervals of the timeaveraged wind speed deficit. The results obtained for the near and far wake regions introduce fundamentals in estimate the uncertainty in wind speed deficit of a single wind turbine wake and concludes that a systematic uncertainty quantification (UQ) framework for wind turbine wakes may be a useful tool to wind energy projects.
\end{abstract}

Keywords: Uncertainty quantification, parametric statistics, wind turbine wakes, computational model, wind energy efficiency and reliability

\section{INTRODUCTION}

With the maturity of wind energy technologies, the next step to decrease the cost of electricity in a wind farm project is by increasing the reliability of wind farms. Atmospheric boundary layer conditions, inflow turbulence, and aerodynamic interactions between turbines, i.e., wakes, are among the leading causes of significant power losses in wind farms [1]. It is estimated that a range of $10-20 \%$ of the power losses in wind farm installations is due to the wake effect [2]. These losses occur because as the air flows through the wind turbine rotor and interacts with the blades, the wake develops, reducing the wind speed and increasing the turbulence downstream at the next wind turbine. Therefore, the development of methods to minimize the adverse effects of wakes in the power production metrics is of great interest to the wind energy industry. Furthermore, the stochastic nature of the wind resource availability and the random fluctuations of the turbulent flow within the wake bring significant uncertainty in the annual power production [3].

Uncertainty quantification (UQ) is a useful tool to enable computational models to properly capture the stochastic aspects of wind flow. Several models with different levels of complexity/fidelity considering the wind as a stochastic process have been proposed in the last decade. Barone et al. [4] described the use of high-performance computing resources to simulate wind turbines and identify important loading mechanisms present in stochastic wind fields. Guo and Ganapathysubramanian [5] presented a data-driven stochastic model based on the temporal-spatial decomposition of the wind field and an aeroelastic model in order to compute the stochastic response of the wind turbine. Fluck and Crawford [3] developed a simplified version of a standard spectral wind model with reduced numbers of random parameters. Murcia et al. [6] presented a methodology that extends deterministic power and thrust coefficient curves to uncertainty models and to determine the fatigue loads in different components of the turbine. All these previous works are primarily focused on the stochastic modeling of the wind inflow and are limited to the analysis of the wind turbine loads. Only a few works extended stochastic modeling methodologies to the analysis of wakes. Among these, Doubrawa et al. [1] proposed a stochastic model that produced an unsteady asymmetric wake based on large-eddy simulations of an offshore wind farm. Doubrawa's model considered some

\footnotetext{
${ }^{1}$ Corresponding author: stephen.ekwaro-osire@ttu.edu
} 
wake parameters, such as the wake shape and center as random variables; however, no rigorous attempt was made to quantify the uncertainties of the inflow regarding the wake effect. There is a need to increase the levels of understanding of the uncertainty regarding wind turbine wake modeling.

This paper presents an UQ framework to the wind turbine wake effect considering the randomness of the inflow. Random mean wind speeds are used to feed a turbulent wind flow generator (TurbSim) and produce the scenarios of the wind turbine inflow. Then, a wind turbine aeroelastic model (FAST) and a wake engineering model (FLORIS) simulates the wind turbine response and the wind turbine wake. Parametric statistics are used to determine the probability distributions and the confidence intervals of the time-averaged wind speed in the wake region, in which the uncertainties of the wind inflow are propagated through a Monte Carlo simulation scheme. The detailed methodology is given below.

\section{METHODOLOGY}

The procedure presented in this section is preceded by a brief introduction of the models that are used in this study.

\subsection{Wind Resource}

During the development of a wind energy project, the wind resource assessment counts with the specific site wind data measurements that cover a year or a couple of years. For this purpose, Weibull distribution has been widely accepted as the statistical model to determine the probability density function (PDF) of the mean wind speed, $V$ (in $\mathrm{m} / \mathrm{s}$ ), in the determined site, which is given by [2],

$$
f_{V}(v ; a, k)=\left\{\begin{array}{ll}
\frac{k}{a}\left(\frac{v}{a}\right)^{k-1} e^{-(v / a)^{k}} & v \geq 0 \\
0 & v<0
\end{array},\right.
$$

where, $f_{V}$ is the PDF of the mean wind speed, $a$ is the scale parameter and $k$ is the shape parameters of Weibull distribution. If the Weibull distribution parameters are unknown, the Rayleigh distribution $(k=2)$ can be assumed to calculate the wind power density as the International Electrotechnical Commission (IEC) standards that assumes Rayleigh distribution to define wind turbine load [7].

Using the mean wind speed data, the power, $P$, that a turbine can extract from the resource is calculated by,

$$
P=\frac{1}{2} \rho A u^{3} C_{P}
$$

where $\rho$ is the local air density (in $\mathrm{kg} / \mathrm{m}^{3}$ ), $A$ is the swept area of the wind turbine rotor (in $\mathrm{m}^{2}$ ), and $C_{p}$ is the coefficient of power that denotes the turbine efficiency.

As observed in Eq. (1), wind speed has a cubic factor in the wind power formula; therefore, a reduction in the velocity of the wind flow causes significant energy production losses in a wind farm. Hence, a turbine takes the momentum out of the wind, and the outflow has a reduced wind speed: the wake effect.
In addition to power production impacts, the wind turbine thrust force, $T$, is also affected by wake interaction, according to the following expression,

$$
T=\frac{1}{2} \rho A u^{2} C_{T}
$$

where $C_{T}$ is the coefficient of thrust, which can be defined as the fraction of momentum absorbed by the wind turbine. Both $C_{p}$ and $C_{T}$ are used in this investigation as inputs to simulate the wake effects. Such coefficients are outputs from the aeroelastic model used to calculate the dynamic response of the wind turbine, which is described in the next sections.

\subsection{Inflow Model}

TurbSim (Turbulence Simulator) is a stochastic simulator, developed by the National Renewable Energy Laboratory (NREL), that numerically generates time series of full turbulent inflow fields. As its user's guide [8] describes, TurbSim uses a statistical model, rather than a physics-based model, to simulate the three-component wind speed vectors at points in a twodimensional vertical rectangular grid that is fixed in space.

The first lines of a TurbSim input file are the request for integer numbers that are used as random seeds to be initialized with the pseudorandom number generator (pRNG). As also detailed in [8], the pRNG are used to create random phases for the velocity time series, one per frequency per grid point per wind component. An option is to not change the random seeds of the pRNG between runs, then the same random phases are created, and it can be used to compare the effects of changing other parameters. TurbSim output, a full-flow field, is an input to the aeroelastic model called FAST (Fatigue, Aerodynamics, Structures, and Turbulence) [9] to assess the response and loading of a wind turbine component. Thus, FAST is employed in this investigation and it is described next.

\subsection{Wind Turbine Dynamic Response Model}

The responses of a wind turbine to wind inflow can be simulated using FAST, which provides a high-fidelity wind turbine simulation with 24 degrees of freedom [9]. FAST is composed of several modules, which interpolate the TurbSimgenerated fields in both time and space incorporating the fluid dynamic features to the simulation. Therefore, to capture a more realistic scenario it is important to have the aeroelastic wind turbine model output feeding a wake engineering model. The wind turbine model selected to this study is the reference NREL 5-MW wind turbine, which is a $90 \mathrm{~m}$ hub height, $126 \mathrm{~m}$ of diameter (D), and has a rated wind speed of $11.4 \mathrm{~m} / \mathrm{s}$ [10]. As mentioned before, FAST is used to calculate the dynamic response of the wind turbine in terms of the power and thrust coefficients, which are the outputs of the wake engineering model as described in the following section.

\subsection{Wake Engineering Model}

In wind farms projects, the spacing between the wind turbines is at least 5 times (5D) and 9 times (9D) their rotor 
diameter in the prevailing wind direction, respectively. For the crosswind direction, the spacing is typically $3 \mathrm{D}$ and $5 \mathrm{D}$, respectively [2]. Besides the wind farm micro-siting, wind turbine controls (such as yaw and blade pitch) can be used to minimize the wake impacts.

FLORIS (FLOw Redirection and Induction Steady State), also developed by NREL with a collaboration of the Delft University of Technology, is a parametric wake engineering model that predicts the average steady-state behavior of wind turbine wakes, and it can also be used to test possible turbine control-oriented strategies and turbine sitting [11]. The input to FLORIS can be field measurements or high-fidelity simulation data. FLORIS contains several wake models available to be employed, and users can add their own [12]. One of the wake parameters characterized in FLORIS is the wind velocity deficit at each downstream location of the wake. Thomas et al. [13] defined this deficit with respect to the velocity in the wake at a fixed location, $u_{w, i}$, and the freestream wind speed, $u_{\infty}$, as,

$$
u_{w, i}(x, y)=u_{\infty}\left[1-2 b_{i} c_{i}(x, y)\right]
$$

where $b_{i}$ is the axial induction factor of turbine $i$, and $c_{i}$ is the wake decay coefficient. The wake decay coefficients are defined as [13],

$$
c_{i}(x, y)=\left\{\begin{array}{cc}
c_{i, 1} & \text { if } r \leq D_{w, i, j, 1}(x) / 2 \\
c_{i, 2} & \text { if } D_{w, i, j, 1}(x) / 2<r \leq D_{w, i, j, 2}(x) / 2 \\
c_{i, 3} & \text { if } D_{w, i, j, 2}(x) / 2<r \leq D_{w, i, j, 3}(x) / 2 \\
0 & \text { if } r>D_{w, i, j, 3}(x) / 2
\end{array},\right.
$$

where $r$ is the radial distance from the wake center line, $c_{i, q}$ is the local wake velocity coefficient for turbine $i$ in wake zone $q$ (where $q=1,2,3$ for each wake zone), and $D_{w, i, j, q}$ is the wake diameter of the wake at turbine $i$ at downstream location $j$ of each zone $q$. These wake coefficients and wake diameters are respectively defined by [13],

$$
\begin{gathered}
c_{i, q}=\left[\frac{D_{r, i}}{D_{r, i}+2 k_{e} m_{U, q}\left(\gamma_{i}\right)\left[x-X_{i}\right]}\right]^{2}, \\
D_{w, i, j, q}=\max \left(D_{r, i}+2 k_{e} m_{e, q}\left(\gamma_{i}\right)\left[x-X_{i}\right], 0\right),
\end{gathered}
$$

where $D_{r, i}$ is the rotor diameter of turbine $i, X_{i}$ is the downstream location of turbine $i, \gamma_{i}$ is the yaw angle of turbine $i, m_{U, q}$ is the recovery rate coefficient of each wake zone $q$, and $k_{e}$ and $m_{e, q}$ are wake zone expansion coefficients.

The outputs of FLORIS are the wind velocity downstream the turbines, the estimated power production, and the thrust levels at subsequent downstream turbines if a wind farm is simulated. In this paper, the wind velocity downstream is the only quantity considered in this paper.

\subsection{UQ Framework}

According to Zhang [2], in an annual energy production (AEP) estimation of a wind farm, 3\% of uncertainty is often assumed for standard wake modeling. However, to the best of the authors' knowledge, the impact of the stochastic nature of the inflow in the probability distributions of the wind turbine wake parameters is unknown. In the present study, it is proposed a framework to propagate the uncertainty of a random variable into the integration of TurbSim, FAST and FLORIS. This random variable is the mean wind speed at hub height. The flowchart of the framework can be observed in Figure 1.

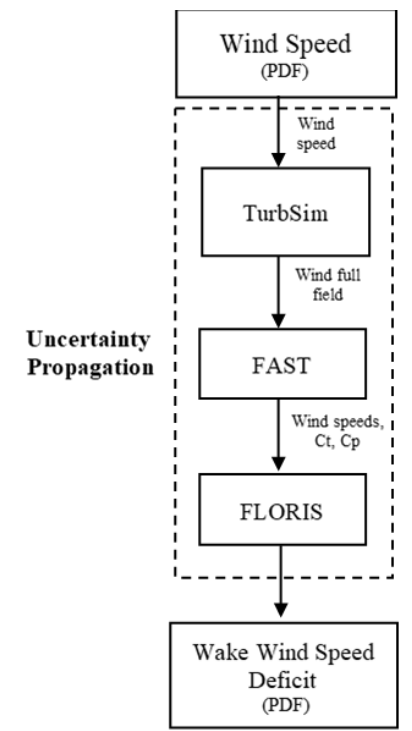

FIGURE 1: PROPOSED UQ FRAMEWORK FOR WIND TURBINE WAKES

First, uncertainties in mean wind speed at hub height are modeled assuming Weibull distribution to determine the wind speed PDF. Based on the IEC standards for a wind turbine type I-C [7], the Weibull shape and scale parameters are respectively defined as $k=2$ and $a=7.5 \mathrm{~m} / \mathrm{s}$. Then, samples are randomly generated for the mean wind speed using the inverse transform method [14]. For this purpose, the wind speeds of $3 \mathrm{~m} / \mathrm{s}$ and 25 $\mathrm{m} / \mathrm{s}$ are used to define the limits based on the cut-in and cut-out wind speeds of the NREL 5-MW turbine [10]. Some sampled mean wind speeds, which is shown in Table 1, are used as input in TurbSim. The other TurbSim model parameters are fixed: wind direction (considered zero degrees), turbulence intensity, and air density (set to $1.225 \mathrm{~kg} / \mathrm{m}^{3}$ ). Likewise, the TurbSim random seeds are also fixed to ensure that the same type of experiment occurred at every run. IEC Kaimal is the spectral model chosen to generate the turbulent wind field. Each TurbSim run is set to have 630 seconds to avoid the transient phenomena at the start of the simulations; and since FAST simulations require that the wind field encapsulate the entire volume of the rotor turbine, the TurbSim grid is set to have a $15 \times 15$ points, $132 \times 132 \mathrm{~m}$. Then, using TurbSim, 30 realizations are generated, each one with 10 minutes data. The 30 values for the mean wind 
speed (WS) and mean shear across the rotor disk calculated in the TurbSim grid are shown in Table 2. Note the differences between the wind speed input (Table 1) and output (Table 2) values from TurbSim.

TABLE 1: SAMPLED MEAN WIND SPEED AT THE HUB HEIGHT (TURBSIM INPUTS)

\begin{tabular}{|c|c|c|c|}
\hline$\#$ & WS (m/s) & $\#$ & WS $(\mathrm{m} / \mathrm{s})$ \\
\hline $\mathbf{1}$ & 14.70 & $\mathbf{1 6}$ & 6.59 \\
\hline $\mathbf{2}$ & 3.97 & $\mathbf{1 7}$ & 11.71 \\
\hline $\mathbf{3}$ & 11.32 & $\mathbf{1 8}$ & 4.16 \\
\hline $\mathbf{4}$ & 8.95 & $\mathbf{1 9}$ & 3.38 \\
\hline $\mathbf{5}$ & 12.13 & $\mathbf{2 0}$ & 4.96 \\
\hline $\mathbf{6}$ & 10.78 & $\mathbf{2 1}$ & 6.51 \\
\hline $\mathbf{7}$ & 13.81 & $\mathbf{2 2}$ & 7.15 \\
\hline $\mathbf{8}$ & 15.60 & $\mathbf{2 3}$ & 4.63 \\
\hline $\mathbf{9}$ & 8.45 & $\mathbf{2 4}$ & 10.82 \\
\hline $\mathbf{1 0}$ & 7.48 & $\mathbf{2 5}$ & 4.82 \\
\hline $\mathbf{1 1}$ & 4.54 & $\mathbf{2 6}$ & 3.60 \\
\hline $\mathbf{1 2}$ & 13.02 & $\mathbf{2 7}$ & 7.80 \\
\hline $\mathbf{1 3}$ & 15.29 & $\mathbf{2 8}$ & 5.78 \\
\hline $\mathbf{1 4}$ & 3.05 & $\mathbf{2 9}$ & 3.35 \\
\hline $\mathbf{1 5}$ & 11.80 & $\mathbf{3 0}$ & 8.15 \\
\hline
\end{tabular}

The next step of the proposed UQ framework is to propagate the uncertainties of the wind speed field at the hub grid to the wake parameters. For this purpose, a non-intrusive sampling technique, the Monte Carlo method [15], is used to run a FASTFLORIS coupled simulations. The TurbSim full fields are used as input in FAST. Test 18 template from the CertTest package is employed here, which have all the detailed characteristics of the onshore NREL 5-MW baseline turbine configurated (such as blades and tower features). Then, all the settings are maintained as the default and fixed through the 30 simulations. From FAST outputs, the power and thrust coefficients, and the respective wind speeds are used as inputs to FLORIS. It is important to mention that no turbine control actions are modeled in this exercise. It is assumed perfect wind turbine rotor alignment with the wind direction and no wind veer. Other inputs required in FLORIS that are related to the mean inflow, came from the TurbSim outputs. Other parameters of FLORIS followed the default settings and assured to be uphold fixed between runs. To simulate wakes, FLORIS requires that a wake model is selected. As Annoni study [12] concluded that the Gaussian wake model that is based on the self-similarity theory was the best representation of wake characteristics under several turbine operations and atmospheric conditions, that is the model used in this investigation. The present study considered a single wind turbine for the "wind farm" layout and the wake analyses are performed considering the wind speed data at 3D $(378 \mathrm{~m})$ and $5 \mathrm{D}(630 \mathrm{~m})$ downstream the wind turbine. As mentioned before, the turbine takes the momentum out of the wind flow, and the outflow has a reduced wind speed. Therefore, the wind flow downstream the turbine is referred here as wind speed deficit, a measure that represents how much of the air velocity was reduced (waked flow) in comparison of the free stream inflow.
TABLE 2: MEAN WIND SPEED AND SHEAR AT THE HUB GRID (TURBSIM OUTPUTS AND FLORIS INPUTS)

\begin{tabular}{|c|c|c|c|c|c|}
\hline$\#$ & WS $(\mathrm{m} / \mathrm{s})$ & $\begin{array}{c}\text { Shear } \\
(\mathrm{m} / \mathrm{s}) / \mathrm{m}\end{array}$ & $\#$ & WS $(\mathrm{m} / \mathrm{s})$ & Shear $(\mathrm{m} / \mathrm{s}) / \mathrm{m}$ \\
\hline $\mathbf{1}$ & 14.62 & 0.040 & $\mathbf{1 6}$ & 6.56 & 0.018 \\
\hline $\mathbf{2}$ & 3.94 & 0.011 & $\mathbf{1 7}$ & 11.65 & 0.032 \\
\hline $\mathbf{3}$ & 11.26 & 0.031 & $\mathbf{1 8}$ & 4.14 & 0.011 \\
\hline $\mathbf{4}$ & 8.90 & 0.025 & $\mathbf{1 9}$ & 3.37 & 0.009 \\
\hline $\mathbf{5}$ & 12.07 & 0.033 & $\mathbf{2 0}$ & 4.94 & 0.014 \\
\hline $\mathbf{6}$ & 10.72 & 0.030 & $\mathbf{2 1}$ & 6.47 & 0.018 \\
\hline $\mathbf{7}$ & 13.74 & 0.038 & $\mathbf{2 2}$ & 7.11 & 0.020 \\
\hline $\mathbf{8}$ & 15.51 & 0.043 & $\mathbf{2 3}$ & 4.60 & 0.013 \\
\hline $\mathbf{9}$ & 8.41 & 0.023 & $\mathbf{2 4}$ & 10.76 & 0.030 \\
\hline $\mathbf{1 0}$ & 7.44 & 0.021 & $\mathbf{2 5}$ & 4.79 & 0.013 \\
\hline $\mathbf{1 1}$ & 4.51 & 0.012 & $\mathbf{2 6}$ & 3.58 & 0.010 \\
\hline $\mathbf{1 2}$ & 12.95 & 0.036 & $\mathbf{2 7}$ & 7.76 & 0.021 \\
\hline $\mathbf{1 3}$ & 15.21 & 0.042 & $\mathbf{2 8}$ & 5.75 & 0.016 \\
\hline $\mathbf{1 4}$ & 3.03 & 0.008 & $\mathbf{2 9}$ & 3.33 & 0.009 \\
\hline $\mathbf{1 5}$ & 11.74 & 0.032 & $\mathbf{3 0}$ & 8.10 & 0.022 \\
\hline
\end{tabular}

\section{RESULTS AND DISCUSSION}

To find a PDF that could describe the wake parameter, it is attempted to fit a distribution to the FLORIS outputs data, which can be observed in Figures 2-5. The distributions shown here are Weibull, Lognormal, Kernel, Gamma and Normal. Such data came from the downstream wind speed data points of the center of the turbine at $0 \mathrm{~m}(y / D=0)$, and the tip of the blade at $63 \mathrm{~m}$ $(y / D=0.5)$. Note the wake decay characteristic in the figures. The mean wind speed deficit decreases from 3D to 5D: an approximately $33 \%$ wake decay from $3 \mathrm{D}$ to $5 \mathrm{D}$, which is in accordance with the literature [1]. Figure 2 and 4, which presents data from 3D downstream the turbine has higher data density with low wind speeds than the observed data at 5D represented in Figure 3 and 5. However, the data in these last figures are more spread out in the range of $2 \mathrm{~m} / \mathrm{s}$ to $15 \mathrm{~m} / \mathrm{s}$. The flow at the center $(y / D=0)$ presents the lower wind speeds in comparison with surrounding, which can be seen in $y / D=0.5$.

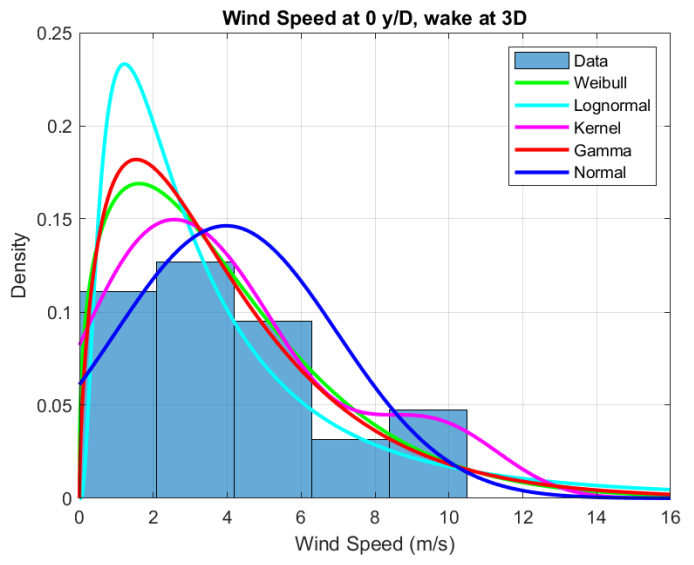

FIGURE 2: PDF OF THE WIND SPEED AT THE HUB HEIGHT AND HUB CENTER - 3D DOWNSTREAM THE TURBINE 




FIGURE 3: PDF OF THE WIND SPEED AT THE HUB HEIGHT AND HUB CENTER - 5D DOWNSTREAM THE TURBINE

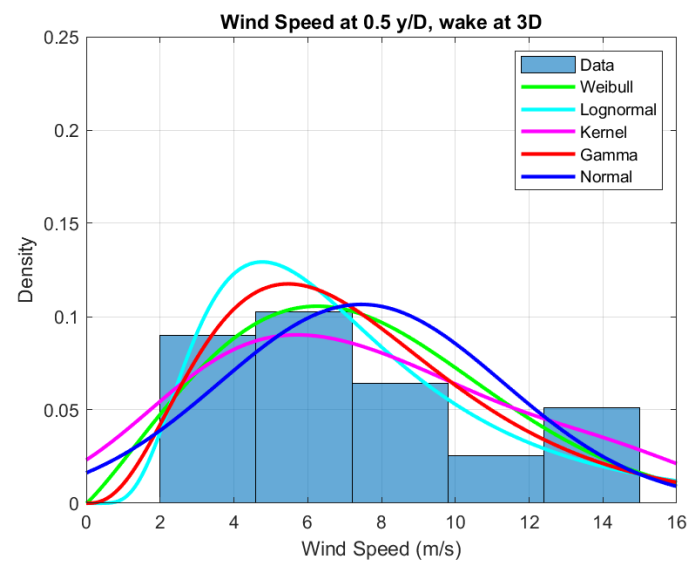

FIGURE 4: PDF OF THE WIND SPEED AT THE HUB HEIGHT. DATA AT 63 METERS FROM THE HUB CENTER AT THE ROTOR SWEPT AREA - 3D DOWNSTREAM THE TURBINE



FIGURE 5: PDF OF THE WIND SPEED AT THE HUB HEIGHT. DATA AT 63 METERS FROM THE HUB CENTER AT THE ROTOR SWEPT AREA - 5D DOWNSTREAM THE TURBINE
The Kolmogorov-Smirnov test (K-S test) is used to compare the distributions, and the Rayleigh and Normal distributions presented similar results. Therefore, to describe the wake events simulated on this analysis, the Normal distribution is chosen, and it is presented in Figures 6 and 7 for 3D and 5D, respectively. The mean is represented by the red curve, while the $95 \%$ confidence interval is the dashed blue lines. Figures 6 and 7 also bring the output of the 30 simulations using the proposed framework. From Figures 6 and 7, it is demonstrated that the wake velocity deficit $\left(U / U_{\text {ref }}\right)$ for a symmetric wake model is maximized at the wake center $(y / D=0)$, and minimized at the wake border $(y / D= \pm 1)$. It is also observed that the relative scattering of the wake velocity deficit is maximized and minimized at those respective locations. It is important to note that this observation occurs relative to the spanwise distance to the hub, and downstream distance from the hub. This is because the uncertainties in the wind speed decrease approaching the wake borders, which represents the free stream wind speed. Furthermore, the uncertainties in the wind speed deficit decrease with increasing downstream distance from the hub, which indicates that the wake recovers towards the free stream wind speed further downstream of the turbine.

In deterministic assessments, the probability of occurrence of a wake and its impacts cannot be accessed. The rule-of-thumb, as mentioned before, is to assume $3 \%$ of uncertainty regarding wake losses. Through the proposed framework presented here, such assessment could be improved studying wake events and its variability as demonstrated. It is important to remember that wind energy production and wake effect analysis are affected by local conditions and type of wind turbine; thus, the quantitative results of this paper cannot be extrapolated as a rule. Nonetheless, this investigation demonstrates that it is possible to study the uncertainty of wake effect in probabilistic scenarios. Future work is going to be dedicated to investigating further the stochasticity of wind scenarios' impact in wind turbine wakes.



FIGURE 6: 95\% CONFIDENCE ENVELOPE OF WAKE WIND SPEED DEFICITS AT THE HUB HEIGHT - 3D DOWNSTREAM THE TURBINE 


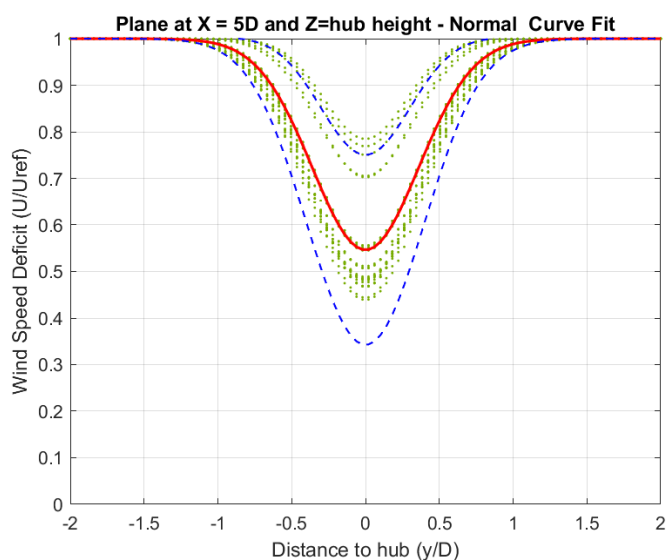

FIGURE 7: $95 \%$ CONFIDENCE ENVELOPE OF WAKE WIND SPEED DEFICITS AT THE HUB HEIGHT - 5D DOWNSTREAM THE TURBINE

\section{CONCLUSION}

This paper presents an UQ framework for wind turbine wakes. Results are obtained for the variability of the wind speed in the near and far wake regions employing wind engineering models for the NREL-5MW reference wind turbine. The results demonstrate that a systematic UQ of the wake effect is possible, and such analysis may be a useful tool to reduce financial risks associated with the uncertainty in the energy production estimation and to guarantee the reliability of wind farm projects.

\section{REFERENCES}

[1] Doubrawa, P., Barthelmie, R. J., Wang, H., and Churchfield, M. J., 2017, “A Stochastic Wind Turbine Wake Model Based on New Metrics for Wake Characterization," Wind Energy, 20, pp. 449-463.

[2] Zhang, M. H., 2015, Wind Resource Assessment and Micro-Siting.

[3] Fluck, M., and Crawford, C., 2017, “An Engineering Model for 3D Turbulent Wind Inflow Based on a Limited Set of Random Variables," Wind Energy Sci., 2, pp. 507-520.
[4] Barone, M., Paquette, J., Resor, B., and Manuel, L., 2012, "Decades of Wind Turbine Load Simulation," 50th AIAA Aerospace Sciences Meeting, Nashville, Tennessee, USA, pp. 1-11.

[5] Guo, Q., and Ganapathysubramanian, B., 2017, "Incorporating a Stochastic Data-Driven Inflow Model for Uncertainty Quantification of Wind Turbine Performance," Wind Energy, 20(9), pp. 1551-1567.

[6] Murcia, J. P., Réthoré, P. E., Dimitrov, N., Natarajan, A., Sørensen, J. D., Graf, P., and Kim, T., 2018, "Uncertainty Propagation through an Aeroelastic Wind Turbine Model Using Polynomial Surrogates," Renew. Energy, 119, pp. 910-922.

[7] IEC, 2005, International Standard IEC 61400-1.

[8] Jonkman, B. J., and Buhl, M. L., 2006, TurbSim User's Guide.

[9] Jonkman, B. J., and Jonkman, J. M., 2016, FAST v8.16.00a-Bjj User's Guide.

[10] Jonkman, J., Butterfield, S., Musial, W., and Scott, G., 2009, Definition of a 5-MW Reference Wind Turbine for Offshore System Development.

[11] Fleming, P., Annoni, J., Scholbrock, A., Quon, E., Dana, S., Schreck, S., Raach, S., Haizmann, F., and Schlipf, D., 2017, "Full-Scale Field Test of Wake Steering," J. Phys. Conf. Ser., 854(1).

[12] Annoni, J., Fleming, P., Scholbrock, A., Roadman, J., Dana, S., Adcock, C., Porte-Agel, F., Raach, S., Haizmann, F., and Schlipf, D., 2018, "Analysis of Control-Oriented Wake Modeling Tools Using Lidar Field Results," Wind Energy Sci., 3(2), pp. 819-831.

[13] Thomas, J. J., Gebraad, P. M. O., and Ning, A., 2017, "Improving the FLORIS Wind Plant Model for Compatibility with Gradient-Based Optimization," Wind Eng., 41(5), pp. 313-329.

[14] Haldar, A., and Mahadevan, S., 2000, Probability, Reliability and Statistical Methods in Engineering Design, John Wiley \& Sons, Inc., New York.

[15] Soize, C., 2017, Uncertainty Quantification: An Accelerated Course with Advanced Applications in Computational Engineering, Springer International Publishing. 